\title{
PENGARUH KOMUNIKASI ORGANISASI DAN KEPUASAN KERJA TERHADAP KOMITMEN ORGANISASI GURU SD SANTO FRANSISKUS DI LAMPUNG
}

\author{
Magdalena Suliyem ${ }^{1}$
}

\begin{abstract}
This study aims to determine the effect of (1) organizational communication, (2) job satisfaction, (3) organizational commitment of primary school sint. Francis In Lampung. This research uses a survey method with a quantitative-causal approach using path analyses. 88 responders were involved by sending their feedback within the questioner. Those responders were decided using simple random sampling among all teachers that working at the predetermined location. The results showed that: first, there are positif influence between the organizational communication and organizational commitment of teachers in schools. Secondly, there is positif influence between job satisfation and organizational commitment of teachers in schools. Third, there is positif influence between organizational communication and job satisfaction of teachers in schools.
\end{abstract}

Keywords: $\begin{gathered}\text { organizational communication, job satisfation, organizational } \\ \text { commitment. }\end{gathered}$

\section{PENDAHULUAN}

Pendidikan merupakan dasar yang kuat bagi setiap individu. Untuk itu peranan pendidik sangat penting di dalamnya. Peranan pendidik/guru sangat berpengaruh dalam mengembangkan kepribadian siswa secara menyeluruh dalam menghadapi tantangan jaman saat ini. Kedudukan pendidik sebagai tenaga professional bertujuan untuk mewujudkan tujuan pendidikan nasional. Salah satu langkah mewujudkan tercapainya mutu pendidikan adalah bagaimana agar masyarakat mempunyai rasa memiliki (sense of belonging) terhadap perkembangan dunia pendidikan.

Guru sebagai pendidik mempunyai peran sentral dalam membangun dan meningkatkan kualitas pendidikan. Komitmen pendidik menjadi hal utama yang dapat menunjang terwujudnya profesionalitas guru dalam mewujudkan pendidikan yang berkualitas. Melalui sekolah, kualitas pendidikan diupayakan dan apa yang dibutuhkan dalam pembangunan manusia Indonesia dapat dipersiapkan dengan baik.

Untuk dapat menjalankan peran, tugas dan tanggungjawab guru secara maksimal, maka sekolah harus dikelola dengan baik. Pendidikan yang berkualitas merupakan hasil kerjakeras sehingga mempersyaratkan adanya kualitas SDM yang unggul dan kompetitif. Untuk itu sekolah harus memiliki guru dengan komitmen tinggi yang mampu berdedikasi tinggi, setia, loyal dan bertanggungjawab dalam menjalankan tugas secara profesional. Guru akan dapat menjalankan tugas dan tanggungjawabnya secara professional apabila

didukung dengan adanya komunikasi oranisasi yang efektif dan kepuasan kerja.

Pendidik yang profesional akan tercermin dalam pengabdian yang ditandai dengan adanya komitmen terhadap organisasi, kepuasan kerja dan adanya komunikasi yang baik dengan pimpinan sekolah serta lingkungan sekerja. Selain itu, ditunjukkan

\footnotetext{
${ }^{1}$ Kepala SD Santo Fransiskus III Jakarta
} 
juga melalui tanggungjawab dalam melaksanakan tugas-tugas sebagai pendidik kepada peserta didik, orangtua, masyarakat dan bangsa.

Komitmen organisasi pendidik dalam organisasi sekolah sangat dibutuhkan. Komitmen organisasi dapat terpenuhi jika ada kepuasan kerja yang terpenuhi. Pendidik yang merasakan bahwa kepuasan kerjanya terpenuhi akan membuat pendidik lebih berkomitmen terhadap organisasi sekolah. Disisi lain, kepuasan kerja pendidik dapat dipengaruhi oleh adanya komunikasi organisasi yang cukup baik pula.

Guru yang bertanggungjawab terhadap tugas dan pekerjaan serta berdedikasi tinggi menunjukkan komitmen yang tinggi tetapi sebaliknya guru yang memiliki kepuasan kerja yang rendah akan berdampak pada komitmen organisainya dan hal ini ditandai dengan meningkatnya perilaku negatif yang berdampak buruk bagi organisasi.

Melihat perkembangan yang terjadi saat ini di tingkat sekolah dasar pada umumnya dan sekolah swasta pada khususnya, masih banyak guru yang memiliki komitmen organisasi yang rendah, hal ini ditandai dengan guru yang mudah menyerah menghadapi tantangan, mudah memutuskan untuk keluar dari sekolah, tidak bersemangat dalam bekerja, melaksanakan pekerjaan dengan terpaksa, kurang terlibat aktif dalam kegiatan sekolah, kurangnya rasa memiliki sekolah sehingga bekerja dengan penuh perhitungan dan tidak mempunyai loyalitas terhadap sekolah.

Selain unsur kepuasan kerja, unsur komunikasi merupakan hal yang sangat penting dalam organisasi agar organisasi dapat berjalan dengan baik. Hambatan yang sering dialami guru dalam membina kerjasama dengan pimpinan sekolah akan berpengaruh terhadap komitmen guru pada sekolah. Komunikasi organisasi yang efektif dapat membangun situasi kerja yang nyaman dan membangun hubungan yang baik sehingga mendorong guru menjalankan profesinya. Efektifitas komunikasi antara guru dengan pimpinan sekolah dan rekan sekerja juga mempengaruhi terwujudnya kepuasan kerja di sekolah. Guru yang merasakan kepuasan kerja yang tinggi akan terus berjuang mencapai tujuan organisasi dengan komitmen yang tinggi.

\section{Komitmen Organisasi}

Stephen P. Robbins and Timothy A. Jugde (2007:47) mengatakan bahwa,"organizational commitment is defined as a state in which an employee identifies with a particular organization and its goals and wishes to maintain membership in the organization." Komitmen organisasi didefinisikan sebagai keadaan di mana seorang karyawan mengidentifikasi diri dengan organisasi, tujuan organisasi dan keinginan untuk mempertahankan keanggotaan dalam organisasi. Selanjutnya menurut Keith Davis, \& John W. Newstroom (1995:259) mengemukakan bahwa,"organizational commitment, organizational degree to which an employee identifies with the organization and wants to continue actively participating in it. Like a strong magnetic force attracting one metalic object to another, it is a measure of the employee's willingness to remain with a firm individu the future. It often reflec the employee's belief individu the mission and goals of the firm willingness to expend effort individu their accomplishment and intention to continue working there." Komitmen organisasi adalah tingkatan dalam organisasi di mana seorang karyawan mengidentifikasi diri dengan organisasi dan melanjutkan keaktifan untuk berpartisipasi di dalam organisasi. Seperti gaya magnet yang kuat menarik satu objek logam lain, itu adalah ukuran dari kesediaan karyawan untuk tetap berada dalam organisasi demi masa depan. Adanya misi dan tujuan dari seseorang dengan kemauan yang kuat untuk berusaha mencapai prestasi dan niat untuk terus bekerja pada organisasi. Selain itu menurut James L. Gibson, Et al (2006:184) mengatakan bahwa, “organizational 
commitment involves three attitude: (1) a sense of identification with the organizational's goals; (2) a feeling of involvement in organizational duties; and (3) a feeling of loyalty for the organization." Komitmen organisasi meliputi tiga sikap: (1) keberpihakan terhadap tujuan organisasi; (2) perasaan terlibat dalam tugas-tugas organisasi dan (3) perasaan loyalitas terhadap organisasi. Sikap-sikap tersebut diatas yang sesuai dan dimiliki seorang guru akan membentuk komitmen dirinya terhadap organisasi. Selanjutnya Steven L. McShane dan Mary Ann Von Glinow (2010:141) menyatakan bahwa,"organizational commitment refers to the employee's emotional attachment in a particularorganization". Komitmen organisasi mengacu kepada ikatan emosional, keberpihakan dan keterlibatan dalam organisasi.

Berdasarkan konsep-konsep yang telah diuraikan di atas dapat disintesiskan komitmen organisasi adalah ikatan emosional seseorang yang kuat terhadap organisasi sehingga mampu bekerja dengan sukarela, mau mempertahankan keanggotaan dan terus menerus berpartisipasi aktif dalam organisasi untuk mencapai tujuan organisasi dengan indikator, (1) keberpihakan terhadap tujuan organisasi; (2) terlibat penuh dalam tugas-tugas organisasi dan (3) loyalitas terhadap organisasi.

\section{Komunikasi Organisasi}

Jean M. Phillips, Stanley M. Gully (2012:270) mengatakan bahwa," organizational communication is the exchange of information among two or more individual or groups in an organization that creates a common basis of understanding and feeling. Organizational communication can move in a variety or directions, and be formal or informal in nature." Komunikasi organisasi adalah pertukaran informasi antara dua atau lebih individu atau kelompok dalam sebuah organisasi yang menciptakan dasar umum pemahaman dan perasaan. Komunikasi organisasi dapat bergerak dalam berbagai arah dan formal atau informal. Selanjutnya menurut N. Pradhan dan Niti Chopra (2008:24) menyatakan bahwa," the authors went further to suggest a minimum of three basic dimensions of organizational communication: (1) message content, (2) technique (for example, rhetorical devices), and (3) channels." Para penulis melangkah lebih jauh untuk menyarankan minimal tiga dasar dimensi komunikasi organisasi: (1) isi pesan, (2) teknik (misalnya, perangkat retoris), dan (3) saluran. Selanjutnya menurut Gary Dessler (2000:457) mengatakan bahwa," organizational communication is subject to barriers and distortion caused by organizational factors such as restricted communication flows different organizational positions of senders and receivers." Komunikasi organisasi tergantung pada hambatan dan gangguan yang disebabkan oleh faktor-faktor organisasi seperti pembatasan komunikasi yang mengalir berbeda dari pengirim dan penerima. Menurut penulis yang sama Gary Dessler (2005:369) dikatakan lebih tegas lagi bahwa," organizational communication is the is the exchange of information transmission of meaning among several individuals or groups throughout the organization." Komunikasi organisasi adalah pertukaran informasi dan transmisi makna di antara beberapa individu atau kelompok di seluruh bagian organisasi. Dengan demikian dapat digambarkan bahwa proses komunikasi organisasi merupakan gabungan seluruh proses komunikasi antar individu atau kelompok dalam organisasi. Menurut Joyhn R. Baldwin, Stephen D. Perry and Mary Anne Moffitt (2004:292) dikatakan bahwa,"organizational communication is the process of creating, sending, and receiving messages in a complex system, which includes a net of integrated internal and external relationship comprising individual working to manage organizational ambiguity and achieve an outcome or goal."

Berdasarkan uraian-uraian yang telah dikemukakan di atas, maka dapat disintesiskan bahwa komunikasi organisasi adalah proses pertukaran informasi antar 
individu dalam organisasi dengan kesamaan makna pesan yang disampaikan. Dengan indikator: (1) kejelasan pesan yang disampaikan antar individu, (2) kesamaan pemahaman akan makna dari pesan diantara anggota organisasi, (3) adanya umpan balik antar anggota organisasi.

\section{Kepuasan Kerja}

Menurut Jennifer M. George, Gareth R. Jones (2012:71) mengatakan bahwa, “job satisfaction is the collection of feelings and beliefs that people have about their current jobs. People's levels or degrees of job satisfaction can range from extreme satisfaction to extreme dissatisfaction."Kepuasan kerja adalah koleksi dari rasa dan kepercayaan orang tentang pekerjaan mereka dengan tingkat atau derajat dari kepuasan kerja yang bisa terbentang dari sangat puas sampai ke sangat tidak puas. Menurut Laurie J. Mullins (2005:7) menjelaskan bahwa,"job satisfaction is more of an attitude, an internal state. It could, for example, be associated with a personal feeling of achievement, either quantitative or qualitative." Sedangkan menurut Robert Kreitner \& Angelo Kinicki ( 2010:170) dijelaskan bahwa,"job satisfaction is an affective or emotional response toward various facet of one's job. This definition implies job satisfaction is not a unitary concept. Rather, a person can be relatively satisfied with one aspect of his or her job and dissatisfied with one/more other aspects. Kepuasan kerja adalah respon perasaan atau emosional seseorang terhadap berbagai aspek pekerjaan. Seseorang dapat relatif puas dengan salah satu aspek pekerjaan, tetapi tidak puas dengan aspek lainnya. Kepuasan kerja dapat diartikan sebagai terpenuhinya respons perasaan atau emosional seseorang terhadap berbagai aspek pekerjaan yang dirasakan berkaitan dengan pengalaman yang menyenangkan atau tidak menyenangkan. Selanjutnya menurut Fred Luthans (1992:114) diuraikan bahwa," ...there are five job dimension that represent the most important characteristics of a job about which employees have affective responses, there are: (1) The work itself. The extent to which the job provides the individual with interesting tasks, opportunities for learning, and the chance to accept responsibility, (2) Pay. The amount of financial remuneration that is received and the degree to which this viewed as equitable vis-à-vis that of others in the organization, (3) Promotion opportunities. The chances for advancement in the organization, (4) Supervision. The abilities of the supervisor to provide technical assistance and behavioral support, (5) Cowokers. The degree to which fellow workers are technically proficient an socially supportive." Ada lima dimensi pekerjaan yang dapat diidentifikasikan mewakili karakteristik yang paling penting dari pekerjaan yang membuat karyawan memiliki respon afektif, yaitu: (1) Pekerjaan itu sendiri. Sejauh mana pekerjaan menyediakan tugas-tugas yang menarik, kesempatan untuk belajar, dan kesempatan untuk menerima tanggung jawab, (2) Gaji. Jumlah uang yang diterima secara adil dalam organisasi, (3) Peluang Promosi. Kemungkinan untuk mengalami kemajuan dalam organisasi, (4) Supervisi. Kemampuan atasan untuk memberikan bantuan teknis dan dukungan perilaku, (5). Rekan kerja. Tingkat dimana sesama pekerja mendukung secara sosial.

Berdasarkan definisi konsep yang telah diuraikan tersebut di atas dapat disintesiskan bahwa kepuasan kerja adalah perasaan senang atau tidak senang yang dialami seseorang terhadap apa yang diharapkan dari organisasi, dengan indikator: (1) perasaan terhadap pekerjaan, (2) perasaan terhadap gaji, (3) perasaan terhadap kesempatan promosi, (4) perasaan terhadap supervisi, (5) perasaan terhadap rekan kerja.

\section{METODE}


Penelitian ini bertujuan untuk menguji pengaruh langsung; (1) komunikasi organisasi terhadap komitmen organisasi, (2) kepuasan kerja terhadap komitmen organisasi, dan (3) komunikasi organisasi terhadap kepuasan kerja. Penelitian menggunakan metode survey dengan pendekatan teknik analisis jalur. Penelitian dilaksanakan di SD Santo Fransiskus di Lampung. Populasi terjangkau penelitian ini sejumlah 112 guru. Sampel penelitian sebayak 88 guru. Analisa data untuk pengujian hipotesis akan dilakukan dengan menggunakan teknik analisis jalur, yaitu teknik yang diterapkan untuk menjelaskan pengaruh antara variabel-variabel penelitian. Sebelum dilaksanakan analisis jalur, uji signifikan regresi dan uji linearitas regresi sebagai prasyarat uji statistik dilakukan pengujian penormalan data dari masing-masing variabel penelitian dengan Uji-Liliefors, Statistik inferensial digunakan untuk menguji hipotesis tentang pengaruh antar variabel dengan menggunakan tehnik analisis jalur.

\section{HASIL DAN PEMBAHASAN}

\section{Pengaruh Komunikasi Organisasi terhadap Komitmen Organisasi}

Dari hasil pengujian hipotesis pertama dapat disimpulkan bahwa terdapat pengaruh langsung positif komunikasi organisasi kerja terhadap komitmen organisasi dengan nilai koefisien korelasi sebesar 0,445 dan koefien jalur sebesar 0,330. Ini memberikan makna komunikasi organisasi berpengaruh langsung terhadap komitmen organisasi. Hasil penelitian ini senada dengan pendapat beberapa ahli di antaranya adalah R.Wayne Pace (2002:41) di dalam jurnal yang ditulis mengatakan bahwa, "communication has influence may gain importance. In fact, without a sense of such influence employees may become dissatisfied and leave the organization; that is, their organizational commitment is likely to decrease. A positive communication encourages commitment to the organization." Komunikasi memiliki pengaruh yang penting, bahkan dapat mempengaruhi karyawan menjadi tidak puas dan meninggalkan organisasi yaitu komitmen organisasi mereka cenderung menurun. Maka komunikasi yang positif mendorong komitmen seseorang terhadap organisasi. Selanjutnya Anne May dan Nicotera (1995:134) menyatakan bahwa," organizational commucation has been developed which posits that "employees who are free to voice their ideas and concerns become involved and consequently become more satisfied, self-actual-ized, identified with, and committed to their work organization. Attention has also been directed at commucation behaviors which can enhance organizational commitment and productifity." Komukasi organisasi telah dikembangkan dan menyatakan bahwa karyawan yang bebas untuk menyuarakan ide-ide dan keprihatinan mereka dan membuat mereka terlibat dalam organisasi berdampak pada terwujudnya kepuasan diri yang sebenarnya, dapat diidentifikasi dengan berkomitmen bagi organisasi dan pekerjaan mereka. Perhatian juga telah diarahkan pada perilaku komunikasi yang dapat meningkatkan komitmen organisasi dan produktifitas. Hal ini dipertegas oleh Richard J Niehaus dan Karl F. Price (1995:6) menyatakan bahwa," the influence and impact of organizational communications activity on enhancing employee commitments." Kegiatan komunikasi organisasi berpengaruh pada peningkatan komitmen karyawan.

\section{Pengaruh Kepuasan Kerja terhadap Komitmen Organisasi}

Dari hasil pengujian hipotesis ke dua dapat disimpulkan bahwa terdapat pengaruh langsung positif kepuasan kerja terhadap komitmen organisasi dengan nilai koefisien korelasi sebesar 0,462 dan koefien jalur sebesar 0,355. Hal ini memberikan makna kepuasan kerja berpengaruh langsung terhadap komitmen organisasi. 
Hasil penelitian ini senada dengan pendapat beberapa ahli di antaranya Coquitt, LePine dan Wesson (2009:102-103) mengatakan bahwa,"job satisfaction has a strong positive effect on organizational commitment. People who experience higher levels of job satisfaction tend to feel higher levels of affective commitment and higher levels of normative commitment. Effects on continuance commitment are weaker." Kepuasan kerja memiliki efek positif yang kuat terhadap komitmen organisasi. Orang yang mengalami tingkat yang lebih tinggi dari kepuasan kerja cenderung merasa tingkat yang lebih tinggi komitmen afektif dan tingkat yang lebih tinggi dari komitmen normatif. Efek pada komitmen kontinyu lebih lemah. Selanjutnya Edwin A. Locke, (2009:28) menyatakan bahwa," another attitudinal variable that is closely related to job satisfaction is organizational commitment, which is of interest to organizations because it predicts who is likely to leave the organization rather than help the organization reach its objective." Variabel sikap lain yang berkaitan erat dengan kepuasan kerja adalah komitmen organisasi, yang merupakan kepentingan bagi organisasi karena memprediksi siapa yang kemungkinan untuk meninggalkan organisasi daripada membantu organisasi mencapai tujuannya. Menurut Lloyd L. Byars dan Leslie W. Rue (1991:303) mengatakan bahwa," employees who are satisfied with their jobs tends to be committed to the organization-these employees are likely to be very loyal and dependable." Karyawan yang merasa puas dengan pekerjaan mereka, cenderung akan berkomitmen kepada organisasi. Karyawan tersebut menjadi loyal dan dapat diandalkan dalam organisasi.

\section{Pengaruh Komunikasi Organisasi terhadap Kepuasan Kerja}

Dari hasil pengujian hipotesis ke tiga dapat disimpulkan bahwa terdapat pengaruh langsung positif komunikasi organisasi terhadap kepuasan kerja dengan nilai koefisien korelasi sebesar 0,323 dan koefien jalur sebesar 0,323. Hal ini memberikan makna bahwa komunikasi organisasi berpengaruh langsung terhadap kepuasan kerja.

Hasil penelitian ini senada dengan pendapat beberapa ahli di antaranya N. Pradhan dan Niti Chopra (2008:21) di dalam jurnal yang ditulis mengatakan bahwa,"... the researcher some work on'Job Satisfaction', since in her own study, she worked on the premise that job satisfaction is to a great extent determined by the 'communication'component as manifest in the varied demands of the nature of the work in all the different professions." Penelitian terhadap beberapa pekerja mengenai kepuasan kerja menyatakan bahwa mereka bekerja atas dasar pemikiran bahwa kepuasan kerja sebagian besar ditentukan oleh komponen komunikasi yang terwujud dalam tuntutan bervariasi dari sifat pekerjaan di semua profesi yang berbeda.

Selanjutnya dalam buku yang sama, buku yang sama, N. Pradhan dan Niti Chopra menjelaskan," communication is effective, it tends to encourage better performance and job satisfaction. People understand their jobs better and feel more involved in them. In some instances they would even voluntarily give up some of their long estabilized privileges because they see that a sacrifice is necessary. Such positive responses of employees support on the basic propositions of organizational behavior-that open commucation is generally better than restriced communication. Komunikasi efektif akan cenderung mendorong kinerja yang lebih baik dan kepuasan kerja. Orang memahami pekerjaan mereka lebih baik dan merasa lebih terlibat di dalam organisasi. Dalam beberapa kasus guru bahkan secara sukarela menyerahkan sebagian dari hak mereka selama ada kestabilan organisasi karena mereka melihat bahwa pengorbanan diperlukan.

Sedangkan menurut Cal W.Downs dan Allyson D. Adrian (2004:142) menyatakan bahwa,"...determine what types of communication changes could be made that would increase employee satisfaction. Communication changes needed to prove job satisfaction." 
Memengetahui jenis perubahan komunikasi bisa dilakukan untuk meningkatkan kepuasan karyawan. Perubahan komunikasi diperlukan untuk membuktikan kepuasan kerja.

Berdasarkan uraian di atas jelas terbukti bahwa komunikasi organisasi berpengaruh langsung positif terhadap kepuasan kerja guru, jika komunikasi organisasi meningkat maka akan berdampak pada peningkatan kepuasan kerja guru dan sebaliknya.

\section{Penutup}

Kesimpulan: Berdasarkan hasil penelitian yang dilakukan terhadap guru SD Santo Fransiskus di Lampung, diperoleh kesimpulan penelitian sebagai berikut : 1) komunikasi organisasi berpengaruh langsung positif terhadap Komitmen organisasi. artinya ketepatan komunikasi organisasi yang dirasakan oleh guru mengakibatkan peningkatan komitmen organisasi guru SD Santo Fransiskus di Lampung. 2) Kepuasan kerja berpengaruh langsung positif terhadap Komitmen organisasi. Artinya peningkatan kepuasan kerja yang diyakini guru mengakibatkan peningkatan komitmen organisasi guru SD Santo Fransiskus di Lampung, 3) Komunikasi organisasi berpengaruh langsung positif terhadap kepuasan kerja. Artinya ketepatan komunikasi organisasi yang dirasakan guru mengakibatkan peningkatan kepuasan kerja guru SD Santo Fransiskus di Lampung.

Saran: Berdasarkan penelitian yang telah dilakukan, dapat disampaikan saran-saran yang dapat meningkatkan komitmen guru diantaranya sebagai berikut: 1) Bagi Yayasan Pendidikan Katolik di Wilayah Lampung. Hendaknya Yayasan Pendidikan Katolik di Wilayah Lampung yang menaungi Sekolah Dasar Swasta Katolik di wilayah ini mampu menjawab berbagai permasalahan yang dihadapi kepala sekolah dan para guru secara memadai untuk mendukung terwujudnya keefektifan komunikasi organisasi dan kepuasan kerja guru. Adanya komunikasi organisasi yang efektif dan guru yang bekerja dengan perasaan senang akan mempengaruhi guru untuk mampu mewujudkan komitmen yang tinggi di sekolah guna mencapai tujuan pendidikan. 2) Bagi Kepala Sekolah Dasar Swasta Katolik di Wilayah Lampung. Hendaknya para kepala sekolah dalam wilayah ini, dapat mengupayakan komunikasi organisasi yang lebih efektif dengan setiap guru dibawah pimpinannya, dan memperhatikan perwujudkan dimensidimensi penting dari pekerjaan guru yang dapat menciptakan kepuasan kerja dalam diri guru. Keefektifan komunikasi di sekolah yang baik dan terus menerus diupayakan oleh kepala sekolah terhadap setiap gurunya, serta kepuasan kerja guru yang tinggi akan memungkinkan para guru mampu bekerja secara professional, bertanggungjawab dan totalitas yang tinggi sehingga komitmen guru dapat dibangun dan diperkokoh demi tercapainya tujuan sekolah. 3) Bagi Ketua Yayasan Sekolah Santo Fransiskus di wilayah Lampung. Bagi pemangku jabatan di yayasan hendaknya dapat berusaha secara optimal untuk terus membangun komunikasi yang efektif. Komunikasi efektif yang diupayakan akan dapat mempermudah sekolah, pimpinan dan guru untuk melaksanakan tugas dan tanggungjawabnya. Selain unsur komunikasi organisasi, perlu juga mengedepankan dan mengupayakan terus menerus hal-hal yang mendukung terciptanya kepuasan kerja guru. 4) Bagi Guru di Sekolah Dasar Santo Fransiskus di wilayah Lampung. a) Guru sebaiknya dapat membangun dalam dirinya hal-hal yang memungkinkan terwujudnya dimensi-dimensi kepuasan kerja dan keefektifan komunikasi sebagai guru. Dengan komunikasi yang efektif serta berkualitas dan kepuasan kerja yang tinggi, guru akan semakin terdorong untuk lebih berkomitmen terhadap sekolahnya.b) Guru membantu 
rekan kerja maupun kepala sekolah dan pimpinan yayasan, sehingga terjalin kerjasama yang baik agar dapat menciptakan komitmen guru yang tinggi terhadap sekolah.

\section{DAFTAR RUJUKAN}

Baldwin, Joyhn R., Perry. Stephen D, dan Moffitt Mary A. Communication Theories: $H$ Everday Life. Boston: Pearson Education, Inc, 2004.

Colquitt, Jason A., Lepine,Jeffery A. dan Wesson, Michael J. Organizational Behaviour. New York:McGraw-Hill, 2009.

Dessler, Gary. Managing Organizations: in an Era of Change. USA: Harcourt Brace \& Company, 2000.

Dessler,Gary. Management: Leading People and Organizations in the 21st Century. USA: Prentice Hall,2005.

Downs, Cal W dan Adrian Allyson D. Assessing Organizational Communication- Strategi Communication Audits.New York: The Guilford Press, 2004.

George, Jennifer M. danJonesGareth R. Understanding and Managing Organizational Behavior. New Jersey: Pearson Education Inc, 2012.

Gibson, James L., et al. Organizational Behavior, Structure, Processes. New York: McGraw-Hill, 2006.

Organizations: Behavior, Structure, Process. New York: McGraw Hill, 2009.

Davis, Keith \& Newstroom, John W. Human Behavior at Work: Organizational Behavior. New York, McGraw Book Campany, 1995.

Kreitner,Robert dan Kinicki, Angelo. Organizational Behavior. New York: McGraw-Hill, 2010.

Lloyd L. Byars dan Leslie W. Rue, Human. Resources Management (United States of American: Richard D. Irwin Inc, 1991.

Locke,Edwin A. Handbook of Principles of organizational Behviour. UNITED Kingdom: Antony Rowe Ltd, 2009.

Luthans, Fred. Organizational Behavior. New York: Mc-Graw-Hill, 1992.

McShane,Steven L. danGlinow,M.A.V. Organizational Behavior.New York: McGraw-Hill International Edition, 2010.

Mullins, Laurie J. Management and Organizational Behavior. Mateu-Cromo: Pearson Education, 2005. 
Niehaus,Richard J danPrice Karl F. Bottom Line Results from Strategic Human Resource Planning. New York: Springer Scince- Business Media, LLC, 1995.

Pace, R. Wayne. Organizational Dynammism Unleashing Power in the workforce.Lomdon: Quorum Books, 2002.

Phillips,Jean M. dan Gully, Stanley M. Organizational Behavior Tools for Success.USA: South Western Cengage Learning, 2008.

Pradhan,N.danChopra,N.(2008). Commication Skills for Educational Managers an exercise in self study. India: Book Enclave.

Robbins Stephen P. danJugde, Timothy A. Organizational Behavior. New Jersey:Pearson Education, Inc, 2007.

Turniansky,Bobbie danHare, A.P. Individuals and Groups in Organizations. London: Sage Publications. Inc, 1998. 